\title{
Partnering with School Leaders: Principal Assessments of Completers
}

\author{
Randy W. Hetherington \\ Hillary Merk \\ Jackie Waggoner \\ James Carroll \\ Bruce Weitzel \\ University of Portland \\ United States
}

\begin{abstract}
Analysis of one measure in on-going case-study of completer impact on P-12 students, employer satisfaction, has revealed core themes that speak to pedagogical practice and professional dispositions as well as a potential shift in what school leaders consider essential for student and teacher success in the classroom. This work underscores the importance of partnerships and collaboration with education stakeholders in collecting meaningful data to inform continuous improvement within teacher training programs. Findings suggest that a different set of aptitudes, beyond pedagogy and subject disciplines, may need to be measured for their effect on teacher effectiveness to counter previous claims that pre-service training does not contribute to teacher's ability to increase student achievement.
\end{abstract}

Keywords: Educational Partnerships; Teacher Assessment; Teacher Effectiveness; Beginning Teachers; Pre-service Teachers; Program Effectiveness

\subsection{Objective}

In a 2017 on-line survey of 423 active Indiana public school principals regarding the overall quality of new teachers, Shepherd and Devers found that principals "were satisfied with the affective and attitudinal approaches of new teachers but were moderately well satisfied with their general instructional abilities and content knowledge" (p.37). Principals in the survey indicated they were less satisfied with new teacher skills around classroom management, differentiated instruction, professional development, parent communication, and effective assessment. The objective of our study was to determine the impact our completers had on students in their P-12 classrooms and specifically how their principals viewed their performance in terms of pedagogical and dispositional strengths and areas of growth. Collaborating with our partner schools we gathered survey and interview data about completer performance from principals to inform our continuous program improvement efforts. The findings in this regional study inform Standard 4 of the Council for the Accreditation of Educator Preparation (CAEP) requirements for national accreditation whereby "the provider demonstrates the impact of its completers on P-12 student learning and development, classroom instruction, and schools, and the satisfaction of its completers with the relevance and effectiveness of their preparation" (CAEP, 2013, Standards, p.2).

Principals in the Shepherd and Devers (2017) study based their perceptions of new teacher competence against the National Board Standards. The authors noted that principals are often the person(s) most responsible for hiring beginning teachers and for assessing their effectiveness in the classroom. Consequently, their assessments are valuable data for Education Program Providers (EPP) engaged in program improvement and as one of multiple measures used to determine the impact of completers on the P-12 population. Not captured by the Shepherd and Devers data, however, is the change if any, in principal perceptions over time. In our EPP's on-going longitudinal case study conducted in northwest Oregon, there appear to be distinct changes in the nature of principal responses over time. These changes are inclusive of areas of perceived strength and competence of completers, as well as areas where completer training requires greater focus and attention. This article presents the preliminary findings of our on-going case study and reflects upon principal perceptions of completer competence and what implications the changes may have for our EPP's continuous improvement efforts aligned with CAEP standard 5 (CAEP, 2017) and inclusive of the findings from Standards 1 through 4.Educational Program Providers (EPP), beyond the requirements of an accrediting body, seek to improve their programs for pre-service candidates. Feedback from stakeholders regarding completer effectiveness in improving student achievement, in the form of principal perceptions of pedagogical and dispositional performance, is one of multiple measures within our case study designed to inform those continuous program improvement efforts. 


\subsection{Conceptual Framework}

A case study is a method to investigate program impact that necessitates a multiple measures approach (Creswell\& Poth, 2018). Wideen, Mayer-Smith, and Moon (1998) discuss the effective use of case studies in evaluating teacher preparation programs and include cautions around generalizing too widely from limited data. The use of multiple measures within a case study is an approach supported by CAEP (2015, p.5), which identifies case studies as a means to an end for developing and evaluating new measures. CAEP includes an example of using case studies in providing evidence for Standard 4 focusing on completer impact. CAEP guidelines for case studies include: identifying the topic to be studied, generating ideas for change, defining measurements, and testing promising solutions (CAEP, 2015, p.27).Our EPP's case study is focused on assessing completer impact on the P-12 student population using measures including focus groups, work samples, observation of completer practice, and employer satisfaction. Employer assessment of completer impact and satisfaction with completer performance is measured usingboth a survey instrument and an interview protocol.

We chose the face-to-face interview to gather data as "knowledge is constructed in the interaction between the interviewer and the interviewee" (Kvale \& Brinkman, 2015, p. 4) and with the understanding that through the interview we would "understand the world from the subjects' point of view, to unfold the meaning of their experience, to uncover their lived world" (Kvale \& Brinkman, 2015, p. 3).

\subsection{The Instruments}

In 2004, the primary set of standards guiding the operation of our School of Education was a locally developed conceptual framework-what CAEP refers to as a Shared Values Framework. Our EPP sought to gather employer perceptions of completer performance by utilizing survey and interview questions based on the shared values framework, such as: Were our teachers still exhibiting the knowledge, skills, and professional dispositions that had been the foundation of our preparation program (Author(s), 2019)?Our 20-question survey was administered by the Associate Dean (or designate)during visits with volunteer principals who were supervising completers of our program. During the face-to-face interview that followed the survey, four interview questions provided an opportunity for principals to discuss and expand upon their responses. After the 2004 iteration of the survey, in considering additional topics raised by principals during their interview, the survey was expanded to 23 items in eight categories to include questions about teacher use of technology and data-based assessment.The categories relate to teacher attributes as well as pedagogical and assessment skills. In addition to three new items, in 2013 we aligned the instrument with InTASC standards, the primary standards by which programs were evaluated at that time. Since that revision the instrument has remained the same.

The case study was initiated in 2004 and is on-going. The findings reported on in this work reference only the period from 2012 through 2018 where the multiple measures approach had been adopted to gather data for accreditation and program improvement purposes. Beginning in 2004, the survey and interview protocol were used as part of principal interviews every two years. Due to small sample sizes, survey data were analyzed descriptively and transcripts of the interviews were coded using the same two-cycle coding process applied to all qualitative data collected for the larger case study through other measures (Saldaña, 2016). Not all principals who supervise our completers were interviewed for the study. Only principals of completers who submitted a work sample and agreed to have their classroom instruction observed by a faculty member were eligible as we sought to triangulate data between and among the multiple measures utilized in the case study as a whole. Interviews generally were completed in 30-40 minutes as administrators frequently provided detailed answers to the prompts and expanded their responses to include suggestions for the improvement of the teacher preparation program.

\subsection{Analysis of Employer Data}

Interview responses, obtained over time, were analyzed using a constant comparative methodology designed to "generate theory more systematically" and thereby produce themes that are "integrated, consistent, plausible [and] close to the data" (Glaser, 1965, p. 437). Merriam (2016) states that "constant comparative method of data analysis is widely used in all kinds of qualitative studies, whether or not the researcher is building a grounded theory," (p.32) and Charmaz (2014) identifies it as appropriate for generating the type of findings we were seeking due to its inductive and comparative processes. In 2008 O'Connor, Netting and Thomas wrote:

Simply put, constant comparison assures that all data are systematically compared to all other data in the data set. This assures that all data produced will be analyzed rather than potentially disregarded on thematic grounds. It is the time and the process of this constant comparison that determines whether the analysis is deductive and will producea testable theory or whether the analysis is inductive and will build a theory fora particular context. (p. 41) 
Fram (2013), in writing about a constant comparative approach (CCA) outside of grounded theory, summarized the debate surrounding what Glaser and Strauss (1967) referred to as "emergence and theoretical sensitivity" (Fram, 2013, p. 2). The debate questioned the ability of novice researchers to apply CCA in a systematic and purposeful manner. Similar to Fram's approach to her naturalistic inquiry, we too utilized the coding paradigm outlined by Corbin and Strauss (1998) and sought to use "CCA at the early stages of a research project to identify patterns in the data and to organize large amounts of data so as to abstract categories" (Fram, 2013, p. 20).

Following administration of the survey and interview to 44 principal participants, modified Likert scale responses ranging from 1 (Strongly Agree) to 4 (Strongly disagree) with 0 representing a behavior or disposition not observed, were analyzed to determine completer skills or dispositions deemed to be weak in more than $10 \%$ of completers. As an EPP we set the weakness threshold at $10 \%$ feeling that this was enough to warrant discussion among faculty and perhaps indicate the need for further analysis to see if the weakness pertained to a particular program or track. Skills or dispositions that exceeded the $10 \%$ threshold in this analysis were: respectful classroom climate conducive to learning $(11 \%)$; refines plans for instruction based on progress data $(14 \%)$; demonstrates the use of instructional techniques requiring critical thinking and problem solving (14\%); uses classroom time effectively to provide maximum time for learning (11\%); communicates and enforces classroom rules and behavioral expectations(14\%); monitors student conduct and takes appropriate action to maintain an environment conducive to learning (16\%); and when asked can describe a theory-based rationale for his, her or their instructional practices (25\%). When considered by category, there were no areas where principals indicated an issue of consistent importance. This was also true when categories were grouped by pedagogical skills and teacher attributes which suggests further examination of the individual items above the $10 \%$ threshold as concerns may relate to a specific year, course or program track.

\subsection{Findings}

Principal responses to our survey and interview instruments have been collected since 2004 however, as mentioned, this paper addresses only the findings from data collected from participants between 2012 and 2018. The interview instrument consisted of four question prompts given to principals and their responses transcribed. Prior to initial coding the transcripts were considered holistically by the research team and potential first cycle codes established. These codes, along with additional codes that emerged through the first cycle process, were then analyzed for potential categories or themes in two distinct ways. The codes were first considered, categorized and themed as a single data set to see what areas of focus emerged. In this analysis, four distinct themes arose: Learning Environment, Classroom Culture, Relationships, and Teacher Identity.

5.1 Theme 1-Learning environment. This theme arose primarily from three categories that subsumed over 18 first cycle codes distilled into three categories; pedagogy, assessment, and classroom management. Principal responses indicated that these three categories were highly interdependent and typically completers who were experiencing success did so in all three categories and similarly, those who were struggling in one, often experienced related struggles in the other two. Within the pedagogy category, respondents placed particular emphasis on the importance of planning by completers. Those who were successful in planning for student engagement, relevant learning activities, and for differentiation based upon identified student needs experienced few if any issues in classroom management and principals found that they easily collected formative and summative data on their students to use in reflecting upon their instruction.

In the assessment category, principals focused primarily on completer use of data. It was acknowledged that completers were collecting data in a variety of ways but where principals had some concern was what teachers were doing with the data they collected, especially around the pre-requisite skills of learners. Evidence of data-informed changes to pedagogy were noted for many completers and there appeared to be a positive relationship between students who acted upon data collected and a more positive classroom culture classroom with fewer management issues. The third category, classroom management, was comprised of completer skills in coordinating classroom procedures and student conduct, organizing for instruction, and resilience of the teacher when dealing with situations involving heightened levels of stress or anxiety for both the student and the teacher. As with assessment, management of the classroom was seen by principals as strongly linked to the level of planning that preceded instruction and whether or not teachers planned the transitions between activities in addition to the instructional activities themselves.

5.2 Theme 2-Classroom culture. Two categories within this theme, social-emotional learning and at-risk learners, encompassed the six cycle one codes. Notable in this theme is that the codes themselves were broad in scope and addressed aspects of student identity and student culture that varied dramatically from respondent to respondent. Broad codes such as diversity, equity, and trauma were utilized, and each had a plethora of sub codes during cycle one. This was done intentionally as the contexts of the completers and the students they serve varies greatly from school division to school division and even between schools in the same school division. 
Principals reported that completers who were better prepared to be culturally responsive and sensitive to issues of trauma for their students were able to create a learning environment and classroom culture that was conducive to success, both for the students and for the teacher. Also captured within this theme is principal's concern about completers ability to differentiate their instruction and their assessment to meet individual student needs. They felt that completers able to build strong relationships with students and gain a deeper understanding of their abilities and challenges, were able to scaffold learners where needed and often apply elements of universal design for learning to their work for greater impact on learning for all the students.

5.3 Theme 3-Relationships. The theme of relationships included seven codes with multiple sub-codes and these were grouped into three categories: collegiality, intrapersonal, and interpersonal. Collegiality was singled out by principals as being critical to completer impact in that they viewed fellow teachers in the school, district support staff, mentors, and instructional coaches as resources that needed to be accessed and whose assistance and expertise needed to be valued. Principals indicated that success in being collegial often led to a more positive classroom culture, improved learning environment for students, and decreased levels of stress and anxiety among teachers. Decreased levels of stress and anxiety among teachers, principals reported, decreased levels of stress and anxiety for students as well.

Intrapersonal skills including the ability to reflect on practice, reflect on mentorship, and be aware of your own state of mind and body were identified as teacher "self-care" practices that when utilized, resulted in greater impact in the classroom. Regarding completers, this often took the form of principal comments related to maturity, compassion and caring, and mindset. It was indicated by a number of principals that successful completers demonstrated on-going reflective practices and demonstrated good self-care. The interpersonal category was utilized to capture the comments related to interactions with parents, administration, staff colleagues, and students. Principals explained that completers who spent the time to get to know their students and their families were better prepared to accommodate differences and create relevant learning experiences. A few principals noted that completers who had a service mentality often went the extra mile for their students and as a result had positive experiences with parents during formal and informal meetings.

5.4 Theme 4 -Teacher identity.This fourth and final theme represents the categories of professional dispositions and community fit. These categories speak to a number of completer qualities identified by principals. Perhaps most prominent among these qualities is work ethic. Numerous principals commented that when completers put in the requisite time to build relationships, to plan for student differences, to regularly assess student performance against standards, and to reflect on their practice, they were far more likely to succeed in all aspects of their teaching and specifically, improving student achievement. Principals acknowledged that new teachers do not necessarily have the experiences to draw upon and those that accepted that reality as part of their early career identity were the ones who were more collegial and willing to accept mentorship from coaches, mentors, and peers.

Another common cycle one code was mindset. Principals were adamant that those completers who arrive with a professional mindset that values students' needs first and foremost and display a willingness to be a learner as well as a teacher are the ones who experience success early and often. Completers who arrive believing they know it all and who rarely reach out to more experienced colleagues for help, usually struggle in their first years of teaching. The final code of note in this theme is one of community fit. Principals articulated that completers who took opportunities to become involved with the school community beyond their classroom responsibilities often experienced fewer issues with management in the classroom. By community involvement principals eluded to extra-curricular student activities, attendance at student performance and sporting events, and engaging with students during routine supervision.

The second level of analysis that was applied to the interview responses was done by question prompt. The first three prompts in the interview protocol are mapped to the categories and questions from the employer survey as a means of arriving at a deeper, richer understanding of principals' rationale for their Likert scale responses. Interview prompt A addresses eleven employer survey questions, prompt B six, and prompt $\mathrm{C}$ six. Prompt D references another aspect of the case study and is not addressed in this work.

Principals responded to each prompt during their interview based upon their experiences with completers from our institution who are employed at their school. The frequency of each code occurring within the coded transcripts of each interview prompt was tallied. To be considered of value in terms of our program improvement or program success, we felt a threshold of 10 or more appearances, given a minimum tally of 1 and a maximum tally of 24 across all codes, was appropriate given the limited sample size.

In considering interview prompt A, 37\% of principals interviewed did have one or more concerns regarding completer performance while $63 \%$ reported no concerns beyond what they considered to be expected limitations for beginning teachers. For prompt B, $82 \%$ of principals reported completers as having a positive impact on students while $18 \%$ were viewed as having minimal to no effect on student learning. 
Prompt C, regarding respect for diversity and meeting the needs of all children, $84 \%$ of respondents reported that completers addressed the needs of all students and $16 \%$ felt that completers they observed did not demonstrate an appreciable respect for the diversity of learners. The fourth interview prompt simply asked for suggestions for program improvement and as such did not generate a percentage of agreement.

Most frequent among significant codes in respect to prompt A regarding performance was the code "interpersonal" with 24 occurrences. Principals felt that in terms of overall performance, a completers ability to communicate with all stakeholders in a manner that contributed to increased student achievement was the biggest strength and challenge. Their ability as pedagogues (18 occurrences), taking a student focused approach to teaching (18), professionalism (17) and collegiality (16) were the next most prominently occurring codes.

Significant codes in respect to prompt B addressing impact on student learning were again interpersonal (19), pedagogy (17), collegiality (14), and training (13). Again, principals indicated that in terms of impact it was the teacher's disposition toward, and ability to work together with students, district staff, parents, and administration that created impact on student learning equal it seems to their pedagogy and training.

Significant codes in respect to prompt $\mathrm{C}$ which addressed meeting the needs of all students and valuing diversity included interpersonal (22), diversity (15), pedagogy (13), at-risk (13) and compassion (14). In addition to once again valuing who the teachers are and how they go about their practice, coded responses to this prompt clearly indicate that in addition to their training and pedagogy, it is dispositional traits that are providing completers with their successes and challenges in the classroom.

The analysis of the principal (employer) surveys and their responses to the face-to-face interviews have raised a number points for consideration regarding what makes completers effective as beginning classroom teachers and what teacher training institutions may want to contemplate in their continuous improvement efforts.

\subsection{Discussion}

Within the six year period reported in the findings above, there are indications that a shift may have occurred in what principals consider to be strengths and challenges of our completers since data collection began in 2004. A shift that is not based in a particular skill set per se, but rather a change in focus or emphasis from the practical skills and discipline knowledge that were once considered the foundation for success in teaching, to include a broader set of social skills and relational knowledge designed to consider the context and culture of students as well as the pedagogy and processes utilized in teaching and learning. In essence, principal responses to our survey and their follow-up interview have renewed a focus on what Vygotsky (1978) understood as educating the whole child with all aspects of the whole being interrelated.

In studying principal perceptions of new teacher effectiveness, Shepherd and Devers (2017) concluded their review of how principals assess new teachers by indicating the need for further study as to why principals rated (and later selected) prospective teachers the way they did and proposed following up their work using interviews. Our on-going case study of completers is starting to provide some insight into the changing criteria for successful beginning teachers and the requisite challenge these changes represent for EPP's seeking to provide the best possible preparation and training for teacher candidates. Our principal survey and face-to-face interview measures indicate that at least equal to pedagogical skill, and perhaps more critical to teacher success early in their career, are the interpersonal skills required to build relationships with stakeholders, the ability to maintain and develop those relationships to benefit student learning, and an understanding of diversity and difference and how those impact planning, teaching and classroom culture. In short, who teachers are as individuals and professionals early in their career, appears to be as important to improved student learning as how they practice their pedagogical skills.

6.1 Developing interpersonal skills. Notable in the findings for our study was the overarching theme of relationships. Principal comments made it clear that these extend beyond students and parents to include collegial and professional relationships that serve to improve teacher practice and the academic, social, and emotional outcomes for students. Principals identified a teacher's maturity, compassion, and mindset as critical components of successful practice. They acknowledged that beginning teachers are perhaps not as skilled pedagogically as more experienced colleagues, yet those who possessed the interpersonal skills to build strong relationships and who embraced collaborative efforts appeared confident and were more respected by students and parents. In contrast to content training and teaching pedagogies, these softer skills are what many of the principals in this study identified as crucial to beginning teacher success as measured by student achievement and positive classroom culture. This supports current research identifying the value placed on teachers' dispositional attributes by principals (Harris, Rutledge, Ingle, \& Thompson, 2010; Engel 2013). 
6.2 Building and maintaining relationships. In their 2009 study of the impact of training programs on beginning teacher effectiveness Boyd, Grossman, Lankford, Loeb and Wyckoff spoke of their findings as suggestive rather than causal given the imperfect nature of studying the phenomenon of teaching effectiveness. They stated, "when trying to identify what aspects of the preparation contribute to teacher effectiveness in the classroom, we do need to control for differences in teachers' entering characteristics" (p.433). It is these very entering characteristics that principals in our work perceive as possibly equal to pedagogical skill and content knowledge in the success of early career teachers. In a similar way our findings regarding principal perceptions of the importance of teachers forming and maintaining relationships characterized by effective communication with parents, students, and colleagues suggest a possible change in values among educational leaders. Success in school has come to mean many things to students, to parents, and to society as a whole with the global nature of the marketplace and the need to be able to function effectively within it. While it is beyond the scope of this article to explore the strategies that may be needed to address this potential change in value systems among educational leaders, it is a fair warning to EPP's that they must consider how they are, or could be, supported within teacher training programs.

6.3 Understanding diversity and difference. Subsumed within the larger themes of learning environment and skills, and classroom culture, beginning teacher's ability to first understand student differences and the many forms of diversity in today's classrooms, and then their ability to act upon that understanding to differentiate instruction and make learning relevant and engaging were clear markers of success. Perhaps more importantly, principals in this work perceived that not possessing the understanding or skills was a key factor in those beginning teachers who do not succeed and ultimately may leave the profession. Summarizing responses to the interview question regarding diversity, principals appear to believe that how well teachers respond to issues of diversity is contingent on how they view diversity and communicate that view to students and other stakeholders. Possessing the interpersonal skills to impart their understanding of difference in a manner that builds trust, and then support and celebrate those differences, was seen by many principals as a major component of success at any stage of their career.While the concept of diversity is one that is likely referenced in most syllabi of an EPP, it is important to question whether we are able to provide preservice teachers with strategies and skills that will be transferable to the wide variety of contexts they will encounter during their teaching careers.

Given that our study is an on-going one and data from principals (employers) will continue to be gathered and analyzed, these findings may be reinforced or they may evolve as the nature of teaching continues to evolve. What is evident from the findings to date, as illustrated in the discussion above, principals are suggesting there needs to be renewed focus on the softer skills of teacher training if early career teachers are to succeed in meeting the needs of all of their students. They must be able to communicate effectively and build relationships with all educational stakeholders.

\subsection{Significance of the Work}

This article endeavored to use the findings from one of multiple measures from our on-going longitudinal study of program completers, employer surveys and interviews, to inform the program improvement efforts of Education Program Providers, to underscore the importance of partnerships and collaboration with stakeholders, and to further the discussion of constant comparative analysis outside the confines of grounded theory development. In addition we sought to shed some light on what Shepherd and Devers (2017) called the why of early career teacher success and provide direction to EPP for continuous improvement of their training programs. Harris and Sass (2008) stated, "There is no evidence that either pre-service (undergraduate) training or the scholastic aptitude of teachers influences their ability to increase student achievement"(p. 1). Perhaps there is a different set of aptitudes that need to be measured for their effect on teacher effectiveness and student achievement and this is certainly fodder for further research as we look to improve the quality of teacher training for the immediate benefit of students and the long-term benefit of society as a whole. Effective teaching within the P-12 system is a complex process and only by working with and studying practice will we come to understand its many facets and how we as EPP can best serve our students.

\section{References}

Boyd, D.J., Grossman, P.L., Lankford, H., Loeb, S., \& Wyckoff, J. (2009) Teacher preparation and student achievement. Educational Evaluation and Policy Analysis 31(4) pp. 416-440. doi:10.3102/0162373709353129

Council for the Accreditation of Educator Preparation. (2013). CAEP 2013 standards for accreditation of educator preparation. Retrieved from http://www.caepnet.org

Council for the Accreditation of Educator Preparation. (2015). CAEP evidence guide. Retrieved from http://www.caepnet.org 
Carpenter, D. (2014). Assessment of operational effectiveness for education program providers. Journal of Assessment and Institutional Effectiveness, 4(2), 103-115. Retrieved fromhttps://muse.jhu.edu/article/582051

Charmaz, K. (2014) Constructing grounded theory ( $2^{\text {nd }}$ ed.). London: Sage.

Creswell, J. W. \& Poth, C. (2018). Qualitative inquiry and research design: Choosing among five approaches (4th ed.). Thousand Oaks, CA: Sage.

Engel, M. (2013). Problematic preferences? A mixed method examination of principals' preferences for teacher characteristics in Chicago. Educational Administration Quarterly, 49(1), 52-91.

Fram, S. M. (2013). The constant comparative analysis method outside of grounded theory. The Qualitative Report, 18(1), 1-25. Retrieved from https://nsuworks.nova.edu/tqr/vol18/iss1/1

Glaser, B. G. (1965). The constant comparative method of qualitative analysis. Social Problems, 12(4), 436-445.

Glaser, B.G., \& Strauss, A. L. (1967). The discovery of grounded theory: Strategies forqualitative research. New York, NY: Aldine De Gruyter.

Goldhaber, D., Krieg, J. M., \& Theobald, R. (2017). Does the match matter? Exploring whether student teaching experiences affect teacher effectiveness.American Educational Research Journal, 54(2), 325-359. https://doi.org/10.3102/0002831217690516

Harris, D. N., Rutledge, S. A., Ingle, W. K., \& Thompson, C. C. (2010). Mix and match: What principals really look for when hiring teachers. Education Finance and Policy, 5(2), 228-246.

Harris, D.N., \& Sass, T.R. (2008) Teacher training, teacher quality, and student achievement. Washington, DC: National Center for Analysisof Longitudinal Data in Education Research.

Kvale, S. and Brinkmann, S. (2015) Interviews: Learning the craft of qualitative research interviewing ( $3^{\text {rd }}$ ed.). Sage Publications, Thousand Oaks, CA.

Merriam, S.B.\&Tisdell, E.J. (2016) Qualitative research: A guide to design and implementation. San Francisco: Jossey-Bass.

O'Connor, M. K., Netting, F. E., \& Thomas, M. L. (2008). Grounded theory: Managing thechallenge for those facing institutional review board oversight. Qualitative Inquiry, 14(1), 28-45.

Saldaña, J. (2016). The coding manual for qualitative researchers ( $3^{\text {rd }}$ ed.). Thousand Oaks, CA: Sage.

Shepherd, D., \& Devers, C. (2017). Principal perceptions of new teachereffectiveness. Journal of Education, 197(2), 37-47. https://doi.org/10.1177/002205741719700205

Strauss, A., \& Corbin, J. (1998). Basics of qualitative research: Techniques and proceduresfor developing grounded theory (2nd ed.). Thousand Oaks, CA: Sage.

Vygotsky, L. S. (1978). Mind and society: The development of higher psychologicalprocesses. Cambridge, MA: Harvard University Press

Author(s). (in press) Using case studydata of completers as evidence in a continuous improvement model. In Jackson, C., Meyer, S., \&Carinci, J (Eds.) Linking teacher preparation program design and implementation to outcomes for teachers and students. Charlotte, N.C.: IAP.

Wideen, M., Mayer-Smith, J., \&Moon, B. (1998). A critical analysis of the research on learning to teach: Making the case for an ecological perspective on inquiry. Review of Educational Research, 68(2), 130-178. 